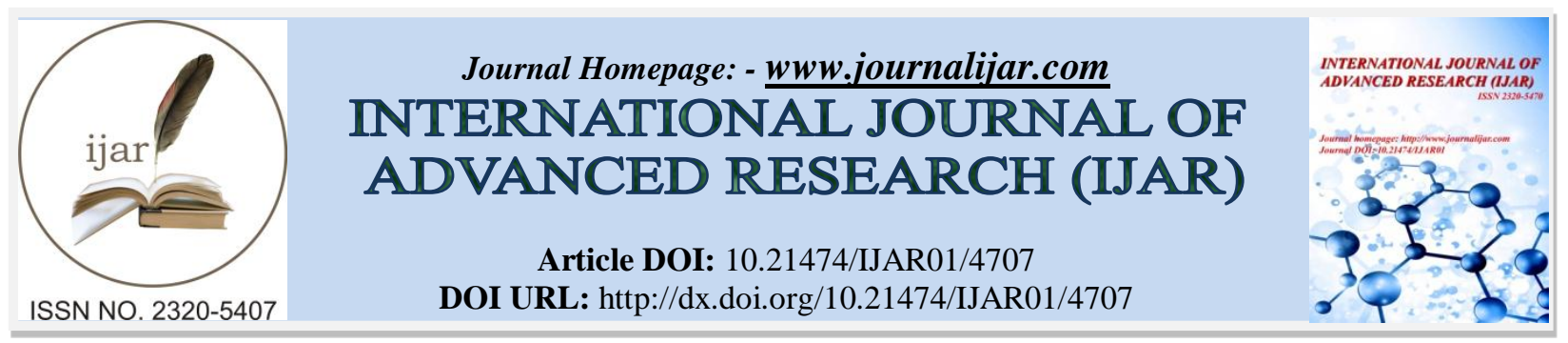

RESEARCH ARTICLE

\title{
ISOLATION AND IDENTIFICATION OF VIBRIO CHOLERA FROM SAWA LAKE.
}

Dr. Ali Anok Najum ${ }^{1}$ and Rima N. Hasan ${ }^{2}$.

1. Department of Nursing .Technical Institute / Samawa, Iraq.

2. Department of Community Health .Technical Institute / Samawa , Iraq.

\section{Manuscript Info}

Manuscript History

Received: 2 May 2017

Final Accepted: 4 June 2017

Published: July 2017

Key words:-

Vibrio cholera, Trimethoprim,

Clindamycin, Linezolid.

\section{Abstract}

Present study aimed to identify the V.cholera in Sawa lake cause there is rare study about contamination of Sawa lake. A total of 10 water samples were collected from Sawa lake in different period, one sample every month from March to December 2016 .Samples were cultured directly on specific medium (Alkaline peptone water, TcBs) bacteria was identified according to cultural characteristics, biochemical tests (Api 20, serotyping and antibiotic sensivity test .

Results showed that $5(50 \%)$ of samples were positive for isolation of Vibrio cholera after further identification for isolated found 1 isolate was positive for $V$. cholera O1 Ogawa serotypes in November . Our isolates (V. cholera O1)was resistant $100 \%$ for Chloramphenicol ,Sulfa, Trimethoprim, Clindamycin and Linezolid, while sensitive 100\% for Ampicillin , Cefotaxime , Ceftriaxone , Erythromycin , Tetracyclin, Nitrofurantin and Gentamycin.

Copy Right, IJAR, 2017,. All rights reserved.

\section{Introduction:-}

Vibrio cholerae, a serious pathogen for humans, has been the subject of intense study for more than a century, yet the discovery that this bacterium is a natural inhabitant of riverine, estuarine, and coastal waters during both temperate and tropical provinces of the world was made only relatively recently (1). Before the late 1970s, transmission of cholera was supposed to arise entirely by person-to-person contact, with epidemics initiated by contaminated water and food. In 1855, Sir John Snow hypothesized that distressing epidemics of cholera are caused by contaminated drinking water (2). In his time, the germ theory of disease had not been proven nor accepted and, obviously, it was not understood that the epidemic strain of V.cholerae was a bacterium naturally occurring in the aquatic environment (3). Therefore, circumstances favorable for multiplication of copepods and related chitinous zooplankton species for which $V$. cholerae is commensal or symbiotic may lead in an arise in the number of $V$. cholerae. The importance of copepods in cholera transmission was confirmed in a study showing that the number of cholera cases in Bangladeshi villages was considerably decreased during a simple filtration technique that efficiently removed the plankton and particulate matter was used to treat drinking water $(4,5)$.

Ocean observation by satellite remote sensing was used to monitor changes in sea surface temperature (SST) and sea surface height (SSH) in the Bay of Bengal. The pattern of changes in these parameters were shown to be related to $V$. cholerae dynamics in coastal, estuarine, and riverine waters of the Bay of Bengal and to the cholera epidemics caused by these bacteria in that region of the world (6). That is, the distinctive seasonal pattern of cholera, in countries where the disease is endemic may be linked with environmental issues and climate that lead both copepod population dynamics and the seasonal peaks in abundance of $V$. 
Cholerae in the aquatic ecosystem of the Bay of Bengal. For that, it is decided that the variables correlated to copepod population dynamics may serve as a proxy for the estimation of $V$. cholerae abundance in the environment. Lobitz et al. (6) were the first to identify the relationship between SST, SSH and cholera incidence using remote sensing, describing changes in coastal ecosystems significantly related to the annual cyclic pattern of cholera epidemics. Significant progress has since been made in modeling interannual variability of cholera epidemics in Bangladesh, employing mathematical models to reproduce the seasonal cycle of cholera $(7,8)$.

\section{Materials and Methods:- samples:-}

A total of 10 water samples were collected from sawa lake/ Al- Muthana - province in Iraq in different period, one samples every month from March 2016 to December 2016.

\section{Bacterial isolation:-}

Each water sample was mixed with equal volume of double strength alkaline peptone water (APW) pH 9.2 (5). Then it was incubated at $37 \mathrm{C}^{\circ}$ over- night. Loopful of incubated samples was streaked at the surface of thiosulphate citrate bile salt sucrose agar medium (TCBS) followed by overnight incubation at $37 \mathrm{C}^{\circ}$. The yellow rounded $3-4$ $\mathrm{mm}$ colonies were picked and streaked over tryptic soya agar (TSA) for further testing by culture the isolates on TCBS and MacConky agar then identification by API20E and biochemical test.

\section{Serological Identification:-}

Slide Agglutination test for $V$. chlerae somatic $\mathrm{O}$ antigens was carried out according method described by (6).

Antibiotic susceptibility test:-

Isolates were tested for susceptibility to nine different antibiotic agents include:

Chloramphenicol, Ampicillin, Cefotaxime, Ceftriaxone, Erythromycin, Linezolid, Tetracyclin, Sulfamethaxazole/Trimethoprim, Clindamycin, Nitrofurantion and Gentamycin(Oxoid /England). The disc diffusion of these antibiotic agents were determined by standard method which recommended in the National Committee for Clinical of Laboratory Standards (NCCLS).

\section{Statistical Analysis:-}

Statistical analysis was conducted by using Chi-square (x2) test to determine the statistical differences among different groups by using a design statistical package for social science (SPSS 19).

\section{Results and Discussions:- Water samples:-}

From 10 water samples, only $5(50 \%)$ were positive for isolation of vibrio cholera where grow on TCBS and oxidase positive after further identification for isolated found 1 isolat were positive for V.cholera $\mathrm{O} 1$ and agglutinate with Ogawa serotypes in November month in addition to isolates other type of Vibrio as V. parahemolyticas 7 (70\%), $\mathrm{V}$. valnificus $9(90 \%)$ and V. alginolyticus $8(80 \%)$ also Areomonas hydrophila $9(90 \%)$ See table (1). This result as like showed by (9) who said that Difficulties associated with isolation of V.cholerae O1 from the aquatic environment can be related to the simple fact that methods for isolating V.cholerae were developed for clinical specimens containing large numbers of actively growing cells, and such methods don't work for environmental samples that are likely to contain cells exposed to and there by adapted to a variety of environmental conditions including, most commonly, low nutrient concentration, $\mathrm{pH}$ in rang (7-8) (Seawater), fluctuating temperatures and $\mathrm{pH}$, variations in oxygen tension, exposure to U.V via sunlight(10)

\section{Identification of vibrio cholera:-}

vibrio cholera cultured are recognized on the basis of colonial morphology which appeared smooth 2-3mm with rounded edges , no lactose fermenter, hemolytic, produce acid/ alkaline without gas and H2S production on TSI medium and yellow colonies on TCBS. Positive for MR-VP . V. cholera organism first recognized when staining with gram stain , which appeared as gram negative cocci, motile and non-spore positive for catalase and oxidase,

The current results of this study are agreement with (11) who mentioned that Vibrio cholera can be easily isolated and identified in the bacteriology Laboratory, Provided, First: that the presence of cholera is suspected and second: 
that suitable specific diagnostic antisera are available. Several specialized selective media have developed since routine entero screening media such as MacConkey agar or Eosin - Methylene Blue agar (EMB). An effective selective medium is Thniosulfate- Citrate - Bile salts Sucrose (TCBS) agar, on which the sucrose fermenting cholera Vibrios produce adistinctive yellow colony, Tellurite Taurocholate Gelatine Agar (TTGA), Sucrose Tellurite Teepol medium, polymexin Mannose Tellurite Agar(12). Cultures that resemble Vibrio 188holera but fail to agglutinate in diagnostic antisera (non agglutinable or Non- O1 group Vibrios) present more of a problem and require additional tests such as oxidase, decarboxylases, inhibition by Vibriostatic disc O129, and the (string test), The string test demonstrateds the property, shared by most Vibrios and relatively few other genera, of forming a mucus- like string when colony material is emulsified in 0.5 present aqueous sodium deoxycholate solution. Additional tests for enteropathogenicity and toxigenesis may be useful. Genetically based tests such as PCR are increasingly being use in specialized Laboratories(7).

\section{Antibiotic sensitivity test:-}

V.cholera $\mathrm{O} 1$ isolated from water of Sawa lake was resistant for Chloramphenicol, Sulfamethaxazole/Trimethoprim, Clindamycin and Linezolid, while sensitive for Chloramphenicol, Ampicillin, Cefotaxime, Ceftriaxone, Erythromycin, Tetracyclin, Nitrofurantion and Gentamycin

our results as same that recorded by (8), all V.cholerae isolates showed a high resistance (100\%) to Ampicillin, Erythromycin ,Cotrimoxazole, Streptomycin, Chloramphenicol and Tobramycin, while all of these were sensitive to the two antibiotics Nalidixic acid and Tetracycline. An earlier study revealed that Non O1 and Non O139 serogroups of the clinical and environmental strains showed multidrug resistance which included resistance to Ampicillin, Tetracycline, Cotrimoxazole, Furazolidone and Streptomycin.

Table 1:- showed the prevalence of Vibrio in sawa lake.

\begin{tabular}{|c|c|c|c|}
\hline Month & type of bacteria & Number of isolates & $\%$ \\
\hline March & $\begin{array}{c}\text { v. cholera } \\
\text { v. parahemolyticas } \\
\text { Areomonas hydrophila }\end{array}$ & $\begin{array}{l}1 \\
1 \\
1\end{array}$ & 10 \\
\hline April & $\begin{array}{c}\text { V. valnificus } \\
\text { V. parahemolyticus } \\
\text { V.cholera } \\
\text { V. alginolyticus } \\
\text { A. hydrophila }\end{array}$ & $\begin{array}{l}1 \\
1 \\
1 \\
1 \\
1\end{array}$ & 10 \\
\hline May & $\begin{array}{l}\text { V. valnificus } \\
\text { V.cholera } \\
\text { V. alginolyticus } \\
\text { A. hydrophila } \\
\end{array}$ & $\begin{array}{l}1 \\
1 \\
1 \\
1\end{array}$ & 10 \\
\hline June & $\begin{array}{c}\text { V. valnificus } \\
\text { V. parahemolyticus } \\
\text { V. alginolyticus } \\
\text { A. hydrophila }\end{array}$ & $\begin{array}{l}1 \\
1 \\
1 \\
1\end{array}$ & 10 \\
\hline July & $\begin{array}{c}\text { V. valnificus } \\
\text { V.cholerae } \\
\text { V. alginolyticus }\end{array}$ & $\begin{array}{l}1 \\
1 \\
1\end{array}$ & 10 \\
\hline August & $\begin{array}{c}\text { V. valnificus } \\
\text { V. parahemolyticus } \\
\text { V.cholerae } \\
\text { A. hydrophila }\end{array}$ & $\begin{array}{l}1 \\
1 \\
1 \\
1\end{array}$ & 10 \\
\hline September & $\begin{array}{c}\text { V. valnificus } \\
\text { V. parahemolyticus } \\
\text { V. alginolyticus } \\
\text { A. hydrophila }\end{array}$ & $\begin{array}{l}1 \\
1 \\
1 \\
1\end{array}$ & 10 \\
\hline October & $\begin{array}{l}\text { V. valnificus } \\
\text { V. parahemolyticus } \\
\text { V.cholera O } 1\end{array}$ & $\begin{array}{l}1 \\
1 \\
1\end{array}$ & 10 \\
\hline
\end{tabular}




\begin{tabular}{|c|c|c|c|}
\hline & V. alginolyticus & 1 & \\
\hline A. hydrophila & 1 & 10 \\
& V. valnificus & 1 & \\
& V. parahemolyticus & 1 & \\
& V.cholerae & 1 & 10 \\
\hline December & V. alginolyticus & 1 & \\
& A. hydrophila & 1 & \\
& V. valnificus & 1 & \\
\hline
\end{tabular}

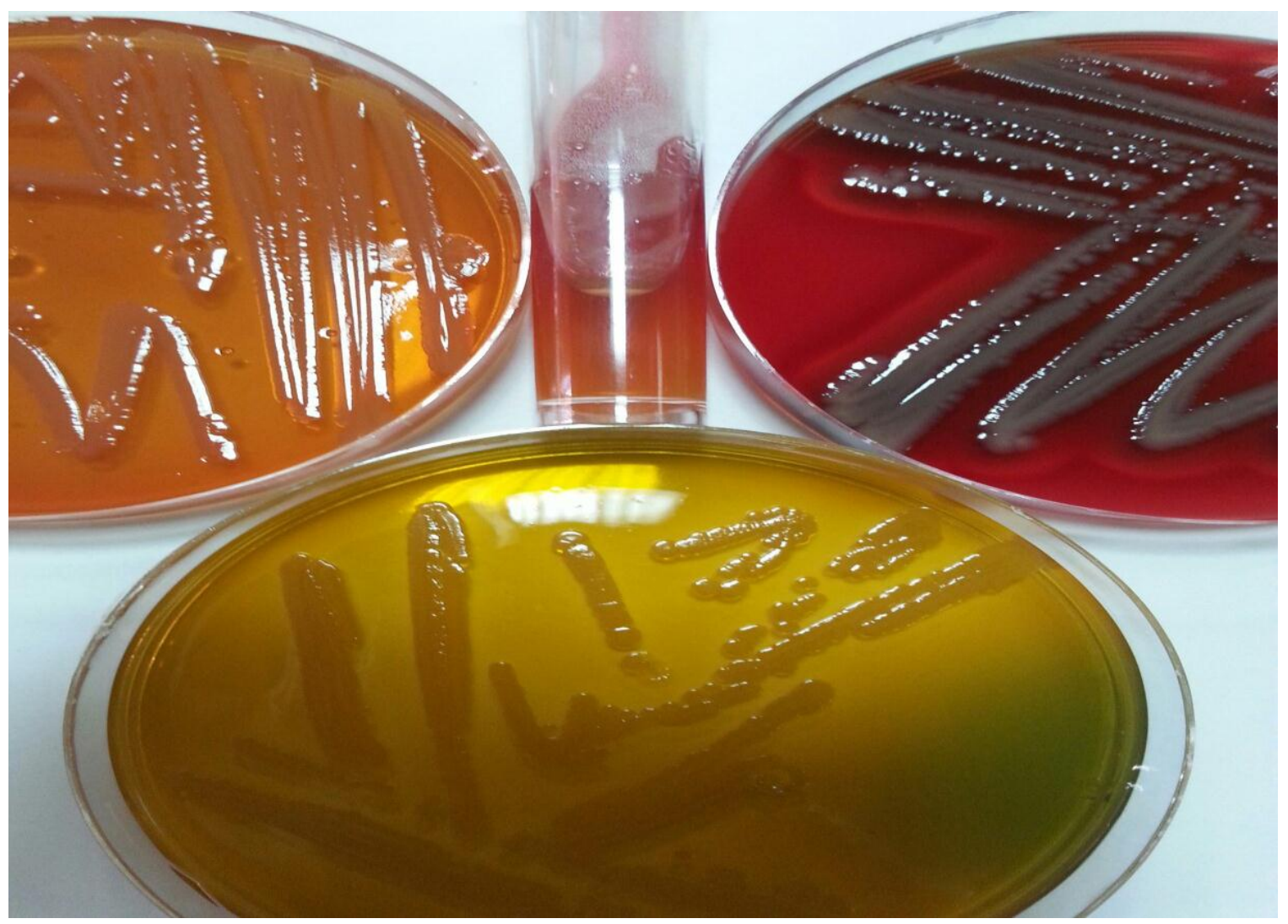

Figure 1:- colonial morphology of Vibrio cholera O1 on TCBS agar, MacConky agar and blood agar showing round, smooth, small and hemolysis colony on blood agar, non-lactose fermenter and yellowish on TCBS. 


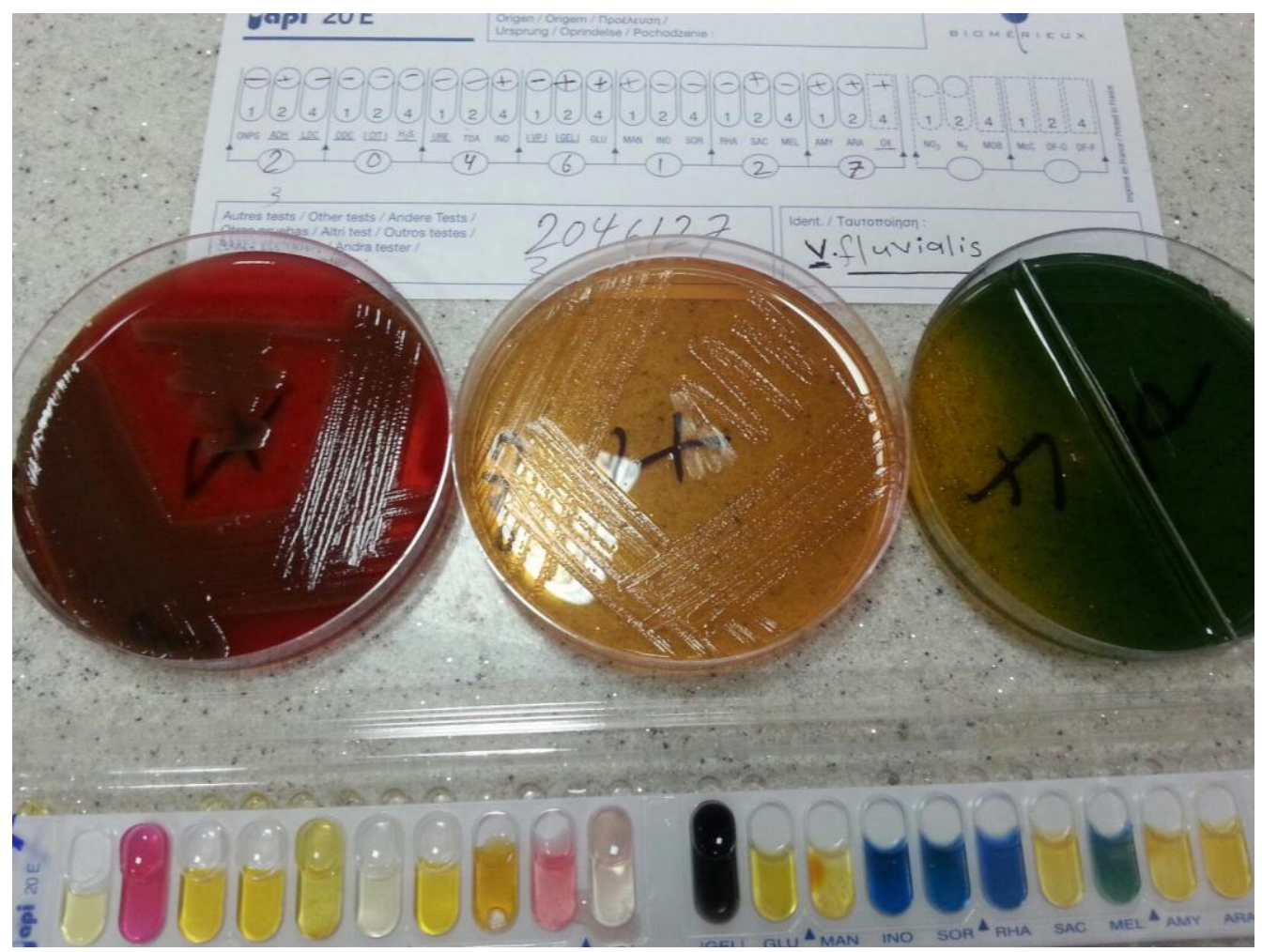

Figure 2:- colonial morphology of Vibrio spp on MacConky agar showing round, smooth, small, pale yellow colonies and non-lactose fermenter and some species ferment and non-ferment for sucrose on TCBS .

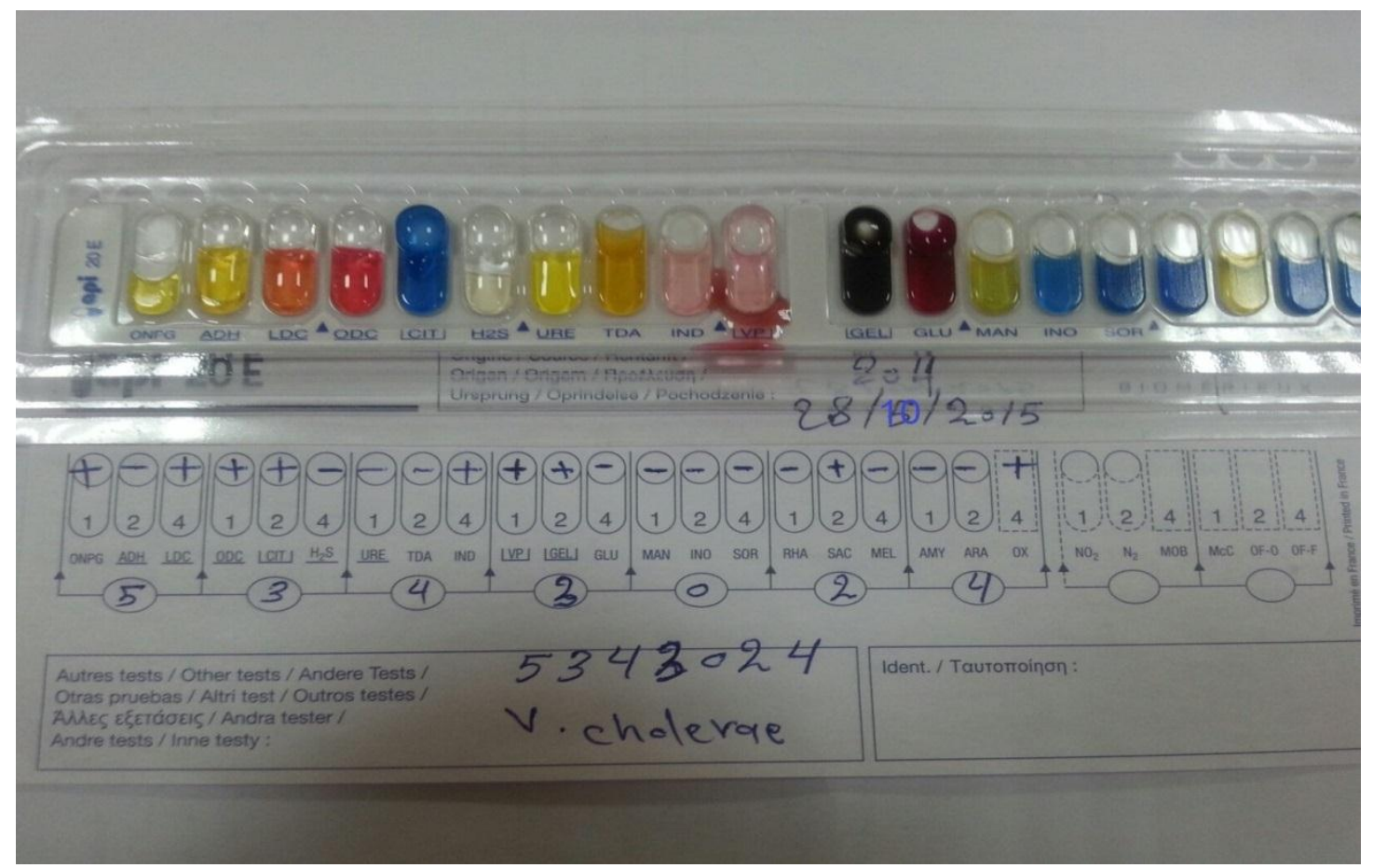

Figure 3:- API20E System for V. cholera isolates. 


\section{Refrences:-}

1. Colwell RR (1996) Global climate and infectious disease: The cholera paradigm. Science 274:2025-2031.

2. Snow J (1855) On the Mode of Communication of Cholera (J. Churchill, London) $2^{\text {nd }}$ Ed, pp 1-162.

3. Johnson S (2006) The Ghost Map: The Story of London's Most Terrifying Epidemic-And How It Changed Science, Cities, and the Modern World (Riverhead Books, New York) p 320.

4. Huq A, et al. (1996) A simple filtration method to remove plankton-associated Vibrio 191holera in raw water supplies in developing countries. Appl Environ Microbiol 62:2508-2512.

5. Colwell RR, et al. (2003) Reduction of cholera in Bangladeshi villages by simple filtration. Proc Natl Acad Sci USA 100:1051-1055.

6. Lobitz B, et al. (2000) Climate and infectious disease: Use of remote sensing for detection of Vibrio 191holera by indirect measurement. Proc Natl Acad Sci USA 97:1438 - 1443.

7. Pascual M, Rodo X, Ellner SP, Colwell R, Bouma MJ (2000) Cholera dynamics and El Nino-Southern Oscillation. Science 289:1766-1769.

8. Koelle K, Rodo X, Pascual M, Yunus M, MostafaG(2005) Refractory periods and climate forcing in cholera dynamics. Nature 436:696-700.

9. Lipp EK, Huq A, Colwell RR (2002) Effects of global climate on infectious disease: The cholera model. Clin Microbiol Rev 15:757-770.

10. Pascual M, Bouma MJ, Dobson AP (2002) Cholera and climate: Revisiting the quantitative evidence. Microbes Infect 4:237-245.

11. Ruiz-Moreno D, Pascual M, Bouma M, Dobson A, Cash B (2007) Cholera seasonality in Madras (1901-1940): Dual role for rainfall in endemic and epidemic regions. Ecohealth 4:52-62.

12. Bouma MJ, Pascual M (2001) Seasonal and interannual cycles of endemic cholera in Bengal 1891-1940 in relation to climate and geography. Hydrobiologia 460:147-156. 